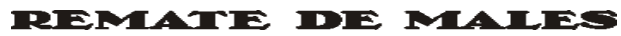

Campinas-SP, v. 38, n. 1, pp. 116-146, jan./jun. 2018

\title{
À MARGEM DO ÍNDICO: OS POBRES E O MAR EM CONTOS MOÇAMBICANOS
}

\author{
Ana Beatriz Braun ${ }^{1}$ \\ Ricardo Luiz Pedrosa Alves ${ }^{2}$
}

Resumo: A partir da leitura de cinco contos moçambicanos, este ensaio pretende discutir uma dupla representação: personagens pobres e mar Índico. São analisados os seguintes contos: "História de Sonto: o menino dos jacarés de pau" (José Craveirinha), "Ziche pescador" (José Craveirinha), "A praga” (Ungulani Ba Ka Khosa), "O outro lado do mar" (Clemente Bata) e "A força do mar de Agosto" (João Paulo Borges Coelho). As questões aqui discutidas passam pela consideração do mar como espaço de sobrevivência das personagens pobres. São analisadas as representações do mar a partir das personagens e dos narradores. A estrutura econômica configura-se como essencial para um melhor entendimento das diversas linhas de força de pertença identitária: local, nacional, transnacional. Concede-se, para tanto, especial atenção à dimensão da mobilidade em relação ao mar e ao espaço geográfico em terra. Tal mobilidade espacial, sugerimos, constitui-se como forma privilegiada para entender a especificidade da modernidade nos contos moçambicanos. Conclui-se que, nos contos analisados, há uma dicotomia entre a representação de mar e a dimensão índica de um imaginário transnacional. Se o mar é representado nos contos como força de atração e repulsão a partir da sobrevivência no cotidiano, a dimensão transnacional do Índico surge menos como imaginário e mais como linha de força estruturalmente significativa para a vida dos pobres, condicionando sua mobilidade marginalizada.

Palavras-chave: contos moçambicanos; mar Índico; personagens pobres.

A discussão sobre a literatura moçambicana referente ao imaginário do Î́ndico é de abordagem crítica recente e usualmente se concentra em alguns objetos, como o imaginário da Ilha de Moçambique (ea significativa

1 Professora do Departamento de Educação (DEPED), Universidade Tecnológica Federal do Paraná (UTFPR), campus Guarapuava: anabeatrizbraun@gmail.com.

2 Professor da Faculdade Guarapuava/Unicentro: ricardopedralves@gmail.com. 
produção poética que a tematizou), ou a presença das personagens indianas e as conexões linguísticas e da cultura material que explicitam a dimensão civilizacional e o imaginário transnacional daquele litoral. Ora, o próprio mar não era, até pouco tempo, considerado como topos privilegiado da literatura moçambicana.

Jessica Falconi (2013, p. 77), uma das autoras mais atentas à questão, defende que o oceano Î́ndico deva ser pensado como unidade analítica, entendendo-o como espaço em si, configurado de modo híbrido e heterogêneo:

o Oceano Índico encontra na representação literária um contraponto que o configura como paradigma epistemológico de alcance mais amplo, suscetível de possibilitar uma equação alternativa das relações entre espaço e identidade, bem como dos conceitos de nação, identidade e, inclusive, de literatura nacional, proporcionando um itinerário crítico e conceptual que aponta para o que vem sendo definido como cultura material.

No ensaio, a autora aborda produções poéticas sobre a Ilha de Moçambique. Há ali o questionamento claro de uma estética oficial e nacionalista da Frelimo (Frente de Libertação de Moçambique) e a introdução de uma perspectiva índica transnacional, mais "friccionada", quanto à identidade e sua simbolização. O tratamento literário da Ilha de Moçambique revisaria margens e fronteiras. Falconi elabora a questão de "fazer o Índico", sugerindo que se parta da cultura material como objeto de pesquisa, buscando ver a fricção das identidades nas coisas, na culinária, nos lugares de troca comercial etc.

Nosso objeto aqui é diferente (contos, e não poemas), e também diverso, o enquadramento crítico quanto à dimensão índica da literatura moçambicana. Optamos pela consideração de contos que representassem a difícil relação entre personagens pobres e o mar Îndico. Intentamos pensar a representação desses corpos populares e sua relação mais "rasa" e "marginal" com o mar. Uma relação ao mesmo tempo de utopia, medo, terror, desconhecimento e subsistência, num cotidiano que vai da dependência à independência. Nos contos, pretendemos ampliar o escopo de análises sobre a literatura de Moçambique e o Índico. Nisso, escapamos ao já bastante esquadrinhado componente do imaginário índico da Ilha de Moçambique, uma espécie de além da terra e ao mesmo tempo uma presença já marítima, já índica.

O conto, estrutura narrativa de tradição oral, é fundamental para se entender a configuração de boa parcela da produção ficcional em 
Moçambique, inclusive quanto aos romances. Ana Mafalda Leite (2012, p. 218) sugere que "o conto parece ser a forma reivindicativa cultural da oralidade e dos antecedentes da tradição narrativa moçambicana [...]". A especialista aponta que a pluralização de contos no interior de alguns romances seria uma sugestão formal à configuração de uma nação diversificada pluriétnica e pluriculturalmente. O conto, portanto, é gênero fundamental para pensar também enquadramentos índicos, transnacionais ou globais da literatura produzida no país.

Assim, a partir da leitura de cinco contos moçambicanos, este ensaio pretende discutir uma dupla representação: personagens pobres e mar Î́ndico. São analisados os seguintes contos: "História de Sonto: o menino dos jacarés de pau” e "Ziche pescador" (ambos de José Craveirinha), "A praga” (Ungulani Ba Ka Khosa), "O outro lado do mar" (Clemente Bata) e "A força do mar de Agosto" (João Paulo Borges Coelho). As questões aqui discutidas passam pela consideração do mar como espaço de sobrevivência das personagens pobres. Serão analisadas as representações do mar a partir das personagens e dos narradores. A estrutura econômica configura-se como essencial para um melhor entendimento das diversas linhas de força de pertença identitária: local, nacional, transnacional. Concede-se, para tanto, especial atenção à dimensão da mobilidade marginal em relação ao mar e ao espaço geográfico em terra. Pensamos a mobilidade como índice apreensível na representação ficcional: mobilidade econômica, familiar e geográfica (o ir e vir do mar e ao mar).

Tal mobilidade espacial, sugerimos, constitui-se como forma privilegiada para entender a especificidade da modernidade nos contos moçambicanos. Pensamos que, nos contos analisados, há uma dicotomia entre a representação de mar e a dimensão índica de um imaginário transnacional. Se o mar é representado nos contos como força de atração e repulsão a partir da sobrevivência no cotidiano, a dimensão transnacional do Î́ndico surge menos como imaginário e mais como linha de força estruturalmente significativa para a vida dos pobres, condicionando sua mobilidade marginalizada.

Na praia, na cidade (e mesmo no interior), o Índico é capturado no seu cotidiano social. Os sujeitos pobres são fraturados, saciados, esvaziados, afogados e sonhados à beira-mar. Alienados e expropriados, no caso de Borges Coelho. Nele, ainda que haja personagens, não se trata exatamente de sujeitos, mas de entes em dinâmica relação com um mesmo e único corpo popular. Nesse sentido, teríamos nesta análise dois polos: o do mar 
mítico, na narrativa igualmente mítica de Ba Ka Khosa (ainda que sob fundo realista) e o mar racionalizado, o mar instituição social, na narrativa de Borges Coelho (ainda que sob fundo fantástico). Os demais contos estariam contidos no intervalo dessa polarização. Assim, não partimos de ideias prévias sobre transnacionalidade, mas pretendemos verificar essa linha de força nos próprios contos selecionados.

Ao mencionarmos linhas de força, é inevitável que nos concentremos em discussões políticas e econômicas, as quais também são encontradas na tematização conceitual e histórica do Índico. Entendemos que a análise dos contos pode proporcionar um contraponto econômico às leituras mais culturais da dimensão transnacional do Índico na literatura, nesse ponto contribuindo para o adensamento da discussão acadêmica. De fato, o problema da restrição de objetos de análise já foi levantado por Nazir Can (2013, p. 97):

\begin{abstract}
A incorporação do Índico, como eixo temático, extravasa a ilha em si, anunciando um cosmopolitismo e uma modernidade dos quais esses poetas foram os portadores primeiros. No entanto, insistimos, trata-se de um extravasar para dentro do próprio território e não tanto para o outro lado do oceano. [...] Daí que a realidade de outros espaços banhados pelo Oceano Índico acabe por ser incorporada apenas parcialmente, através da representação de personagens que, sendo nacionais e simultaneamente diaspóricas, fazem ecoar o tal outro lado. Importa, neste sentido, salientar o viés "fantasmático" de algumas designações ao outro índico, visíveis em expressões que são já lugares comuns nas respectivas sociedades.
\end{abstract}

Para Noa (2014), o Índico foi em geral uma territorialidade e uma condição estrutural da história desprezada pela produção literária e pela crítica em (e sobre) Moçambique. O estudioso nos mostra, por exemplo, como a Ilha de Moçambique recebeu de poetas, como Luís Patraquim, um tratamento prazeroso, identificando o local à mulher mítica. Nos contos, diferentemente, temos personagens marginalizadas, mas também uma ideia marginal de Índico (além da própria condição marginal de Moçambique no diálogo índico).

O Índico pode ser índice de cosmopolitismo, como adiantam alguns estudos, e haveria aí um perspectivismo que reverteo isolamentogeográfico do imaginário luso de Moçambique em uma possibilidade de inserção transnacional (BRUGIONI, 2014), resgatando tal dimensão do próprio processo histórico milenar, bastante borrado ecensurado, seja no momento colonial, seja no pós-colonial, quando se restringiram a moçambicanidade a enquadramentos homogeneizantes. O cosmopolitismo transnacional é 
evidente se resgatamos a produção poética sobre a Ilha de Moçambique, a presença de personagens indianas nas narrativas, os cruzamentos linguísticos e aqueles antropológicos presentes na cultura material. Mas como pensar na dimensão transnacional índica junto à representação ficcional da vida dos pobres?

É preciso destacar que a linha de força transnacional está também presente na ficcionalização da vida popular. Borges Coelho, nesse passo, concilia bem tal estruturação ao mundo cotidiano dos moradores da baía onde se passa sua estória. Ocorre que, nos outros contos, a manifestação transnacional se dá, antes, como linha de força econômica, movimentando, por exemplo, a força de trabalho. Como linha de força, o cosmopolitismo transnacional deve se haver com seu reverso, o localismo. É o que os contos, e aí, mesmo o de Borges Coelho, oferecem como sua especificidade, reduzindo seus elementos ao rés do chão da subsistência.

Importa-nos, pois, completar a discussão identitária transnacional pela consideração de instâncias como o local, a região, a tribo, a cidade, a família. Samir Amin (2015) propõe o abandono relativo de noções como sistema-mundo em nome de uma análise que se equilibre entre as dinâmicas globais e as locais. A questão, pensamos, é mais a de operacionalizar esse equilíbrio de dinâmicas (como a transnacional e a regional), e menos a de apostar todas as fichas num único enquadramento. De outro lado, uma questão central é não perder de vista, a partir da conquista da diversidade, da identidade friccionada ou do diferente enquadramento (transnacional), dois componentes centrais para a orientação das identidades em Moçambique: trata-se de uma nação periférica e dependente e, ao mesmo tempo, trata-se de um espaço de relações sociais extremamente desiguais, nas quais se sobressai a pobreza e a subalternidade. Nisso, a identidade não é bem lida sem a interlocução com aquelas duas dinâmicas estruturais. O Índico, nos contos, é lugar de trabalho/subsistência, é imposição de terror/respeito, fratura os sujeitos de modo material e espiritual, lugar de morte e também de nascimento (escatológico), lugar selvagem/mítico, mas é também uma possibilidade de desejo.

É nesse sentido que o conto de Borges Coelho é significativo e é usado aqui como contraponto aos demais, pois dialoga com os elementos listados acima, a partir dos outros contos analisados, mas articula uma sistematização que justamente o diferencia das demais construções. Ainda que os populares sejam as vozes predominantes no seu conto, é 
no narrador que acabamos encontrando a representação transnacional e índica do litoral de Maputo. O conto de Borges Coelho, portanto, servenos aqui como contraponto fundamental.

Laura Cavalcante Padilha (2009), discutindo as novas cartografias identitárias presentes nas literaturas africanas de língua portuguesa, sugere a "viagem" como tema recorrente naquelas produções textuais. Trata-se, segundo ela, da viagem como projeção de identidade ealteridade. Nos contos aqui analisados, mais do que a viagem, o próprio trânsito, a movimentação em si, como o ir e vir do/ao mar, constituem elementos significativos em duas dimensões: o movimento não só possibilita a expressão dessas identidades pós-coloniais como engendra, formalmente, dinâmicas ficcionais que a tenuidade da vida burguesa impede que se manifeste na própria interioridade dos protagonistas. Deve-se destacar que a pobreza das personagens se faz numa espécie de aquém do capitalismo, quase fora da estrutura de classes em virtude da dinâmica vital da subsistência. Assim, à ausência de individualização burguesa nos moldes europeus, motor da ficção canônica, de ampla movimentação da psicologia e das relações sociais, o que se tem usualmente na ficção periférica éa movimentação no espaço, seja o dos territórios, das fronteiras, seja o da natureza em sua diversidade.

Pensamos que a discussão sobre a pobreza e o mar deve considerar os diversos enquadramentos (local, nacional, continental, mundial, transnacional) como linhas de força que atravessam diferentemente as diversas situações e contextos. Deve-se evitar o apriorismo essencialista de tais enquadramentos, mas igualmente a perspectiva de englobamento (o local dentro do nacional, o nacional dentro do global etc.). Renato Ortiz (2000, p. 57) postula o entendimento dessas questões a partir da noção de processo transversal. Para o sociólogo, dever-se-ia pensar "o espaço como um conjunto de planos atravessados por processos sociais diferenciados". A noção de transversalidade é importante quando se discute a dimensão do cotidiano, exatamente a mais presente nos contos analisados. O transnacional existe quando se materializa em cotidiano, isto é, quando se torna cultura e estrutura econômica. Nisso, revisa-se mesmo a noção de autenticidade (usualmente atrelada ao ser local). É preciso, pois, a localização (no cotidiano, mas principalmente em termos de percepção crítica das produções culturais) do transnacional, isto é, com os pertencimentos e a noção de espaço desatrelados do meio físico, mas, ao mesmo tempo, reterritorializados como dimensão social. 
Os contos são, usualmente, situações atravessadas por diferentes linhasdeforça, nãoapenasculturais, maseconômicas, geográficas, políticas etc. Tais situações cotidianas têm tal atravessamento diferentemente hierarquizado: falar em linhas de força supõe apreender as condições políticas e econômicas de cada entrelaçamento: "portanto, a situação dos lugares pressupõe acomodações e conflitos. Nela explodem os interesses que recortam as sociedades" (ORTIZ, 2000, p. 63). A mobilidade retratada nos contos é justamente a presença da modernidade enquanto linha de força desterritorializante, operando um desenraizamento da força de trabalho, dos indivíduos e das concepções de mundo. $\mathrm{O}$ que não perde de vista as demais dimensões culturais desse espaço Índico transnacional.

Destacamos, por fim, que a sequência de contos analisados obedece também a um movimento que pretendemos claro. Os contos estão dispostos aqui numa perspectiva crescente quanto à percepção da condição transnacional e oceânica do Índico. Em Craveirinha, primeiro um conto no qual a própria entrada no mar significa a morte e, depois, um conto de pesca de cabotagem. Em Khosa, a consciência do desacato simbólico ao mar e suas consequências. Em Bata, a utopia crítica do "outro lado do mar". E em Borges Coelho a conjunção de diferentes perspectivas (a dos pobres, a poética, a científica, a transnacional) sobre o mar, que se faz, assim, Oceano Índico.

\section{CRAVEIRINHA E O MAR ÍNDICO COMO CARRASCO COLONIAL}

Em Hamina e outros contos (1996), foram reunidos textos de José Craveirinha, publicados originalmente no semanário O Brado Africano, em 1955. São textos de ocasião, na maioria redigidos às pressas para cobrir faltas de artigos. Do livro, retomamos para análise os contos "História de Sonto: o menino de jacarés de pau" e "Ziche pescador" (este, de somente duas páginas).

Nos dois contos, ocorre a morte no mar. A mãe de Sonto, Mamana Sambeca, vive de recolher amêijoas (um molusco) na areia da praia, vendendo-as aos proprietários da cidade, representados no conto pela personagem D. Brígida. O conto conjuga a descrição indiciária da exploração econômica (na negociação com D. Brígida e no comentário preconceituoso desta no final do texto) à articulação íntima entre o corpo da mãe, submetido ao trabalho extenuante, e o corpo do filho, o bebê Sonto 
que não se descola do corpo de Sambeca enquanto ela trabalha. A mãe é quem articula essa intimidade com o filho: “- É dôz escudo, muhanu - e deu um jeito ao pequenino Sonto que chupava o seio” (CRAVEIRINHA, 1996, p. 41).

O rompimento dessa intimidade umbilical (na carência) é justamente a ocasião para a morte da mãe de Sonto. Na praia, de madrugada, Sambeca afunda o pé na areia e recolhe as amêijoas. Cansada, deixa o filho no chão. O mar, recolhido de manhã, faz com que Sambeca vá cada vez mais longe. Quando volta já é tarde, a maré subiu, a luta com as águas está além das forças e apenas Sonto sobrevive: "Um mulungo veio nadando e levou Sonto” (CRAVERINHA, 1996, p. 45). O avanço pedestre em direção ao mar, numa condição extremada de carência, conduz a personagem à morte.

Ao fim do conto, Sonto é um menino "velho de seis anos" vendendo jacarés de pau no porto. Sua incorporação do lugar marginalizado da mãe tem a dimensão cíclica de um processo de exploração de "cem anos de fomes e sem escola" (CRAVEIRINHA, 1996, p. 46). O autor compõe em poucas pinceladas o porto como zona intercultural, mas a fim de ressaltar a estratificação social: barcos com turistas brancos, os mavikes (trabalhadores) e o excluído de tudo que é Sonto, "sem sapato, sem casa" (p. 46). Percebe-se que o aspecto transnacional é aqui lido em dupla chave: a racial e a econômica. Craveirinha acaba por não demonizar os brancos como um todo (ainda que haja D. Brígida e os turistas do fim do conto), pois é um branco quem salva Sonto do afogamento. ${ }^{3}$

O quadro da estratificação social se delineia com os turistas brancos, mas principalmente a partir dos mavikes. O termo provém de week e mostra o descompasso de uma denominação trabalhista moderna (a remuneração semanal) com uma realidade de condenação absoluta, já que o destino de todo mavike, sem aposentadoria, era usualmente o da mendicância.

A condição final de Sonto tem uma ambivalência extrema: ao mesmo passo que é a reiteração da exploração sofrida pela mãe, é igualmente manifestação de resistência (como também a ida ao mar dos pescadores ao fim de "Ziche pescador"). No poema "Sangue da minha

3 José Craveirinha, como se sabe, perdeu cedo sua mãe (ronga), passando a viver com o pai (algarvio), o que confere ao conto um espelhamento biográfico sugestivo. A identificação com Sonto, nome pelo qual o próprio poeta era chamado na infância, se estrutura sob um projeto intelectual para a independência de Moçambique. No limite, tanto o poeta quanto o menino pobre acabam sendo mártires da mesma situação colonial. 
mãe",4 Craveirinha retomava o espetáculo da resistência zulu, o Xigubo (com teor identitário nacionalista), anunciando de forma reiterativa e expansiva que iria atender ao chamado da mãe: "Oh, sangue de minha Mãe/xigubo está chamar/xigubo está chamar/e eu vou entrar no xigubo sangue de minha Mãe!" (CRAVEIRINHA, 2010, p. 50). A resistência do pobre em Craveirinha, assim, é também uma outra face da resistência guerreira de cunho nacional-autonomista. O mar, na condição de lugar da subsistência, é vivido no seu limite. Dos contos aqui discutidos, Mamana Sambeca é a personagem que menos avança ao mar, e mesmo assim é por ele engolida. O passo em falso só ocorre em virtude da vida colonial e sua expropriação dos pobres, configurando personagens marginalizadas.

O mar Índico, no conto, é síntese do processo colonial de exploração, sendo também espécie de espectador indiferente aos dramas humanos de uma sociedade extremamente desigual. $\mathrm{O}$ mar se estrutura como carrasco para as personagens de Craveirinha. Pode-se dizer que Sonto não apenas continua na situação de exploração de Sambeca, mas já a vivencia desde o momento de sua concepção, pois o vemos desde o início do conto atrelado ao corpo explorado da mãe.

Em "Ziche pescador", Craveirinha repete a atomização das personagens, sujeitos que vivem no limite porque desafiam a natureza. $\mathrm{O}$ narradoroptapor retratarosindivíduossolitariamente, poisoindivíduoéao mesmo tempo o retrato do coletivo, amplificando o individual justamente ao não ser retratado em sua subjetividade, mas em sua alienação. No plano econômico transnacional, os pobres estão isolados e se tornam trabalhadores intermitentes sem estabilidade. Assim, a atomização do sujeito acaba sendo também a atomização da narrativa. No curto conto, descrevem-se o processo de trabalho e as condições meteorológicas do céu. Ziche vai permanecer no mar apesar das más condições, pois tem um patrão colonial: o imposto.

O imposto, num conto tão pequeno, é citado três vezes. O último dia do imposto se impõe como condição para que Ziche vá ao limite, como também Sambeca, como o menino Sonto e como os mavikes do conto anterior. Em discurso indireto livre, possibilitando a irmanação de narrador e personagem, o herói socialista de Craveirinha é o trabalhador que se sacrifica, ainda que não coletivamente, pois a pobreza conduz à alienação atomizada desses sujeitos. Temos um retrato que configura uma

4 Segundo Matusse (1997), o poema "Sangue da minha mãe" mostra como o poeta reclama pela via materna sua pertença cultural. 
estratificação que opõe o trabalho à natureza: Ziche aparece no mar com os peixes e sua única reflexão é saber se vai ter tempestade e se pagará o imposto.

Craveirinha faz a reiteração de uma condição colonial, contrapondo o lugar praticamente nenhum destinado ao necrológio de Ziche (que o intelectual engajado toma para si), numa relação de jornais que não mencionam mais uma morte entre outras, ao processo de reprodução da exploração, com os trabalhadores que, ao fim do conto, vão ao mar repetir o itinerário de riscos de Ziche.

\section{O MAR COMO NOME DA MORTE EM UNGULANI BA KA KHOSA}

Ungulani Ba Ka Khosa publicou Orgia dos loucos em 1990. O conto "A praga", presente no livro, abre com o seguinte trecho:

Sonhou com o mar. Viu-se a correr sobre a areia branca sob o olhar da lua que atirava os raios às águas, às ondas, às areias e às árvores que se agitavam, dando à noite uma beleza nunca vista na sua curta e atribulada vida, pois desde que nascera no meio das águas do mar, por entre as ondas revoltas que acompanhavam o estertor da mãe que se atirava para um e outro lado do barco, a infelicidade abraçara-o de tal modo que o pai sentiu-se dorido a partir do momento em que vira a mãe contorcendo-se de dores, gritando, chorando... (KHOSA, 2008, p. 17)

O fluxo segue e só temos um ponto final quase ao fim da página. $\mathrm{O}$ sonho é cortado pela consciência do nascimento no mar e todo o parágrafo acompanha o parto. O protagonista Luandle nasce no mar, sob o signo da dor, mas o conto se inicia sob as perspectivas do sonho e da "beleza nunca vista" (o que é uma primeira ambivalência do mar). Luandle começa a nascer "com os pés, como se em terra firme quisesse pisar..." (KHOSA, 2008, p. 18). São duas excepcionalidades: nascer no mar e nascer pelos pés. Há aí interdição e contravenção. Perceba-se que toda a consciência inicial é a do pai, e assim será pelo conto todo: a interioridade se concentra no patriarca.

Após desembarcarem, são acolhidos por familiares e amigos, numa comunidade de valores e acolhimentos. Tal vinculação comunitária é estruturante e fundamental para a legitimação de passos subsequentes na vida. Em Khosa, porém, trata-se de um falso anúncio ao leitor. Nele, a vida comunitária, bem como a família e os lugares por onde circular Luandle, 
cairão todos abaixo, submetidos a uma destruição escatológica. É como se o nascimento da personagem precipitasse a "praga": a morte da mãe, o fim da pesca etc. Preocupado, o pai leva a criança ao feiticeiro, que se limita a indicar o nome Luandle, "designação que o mar leva nestas terras tsongas” (KHOSA, 2008, p. 19). Há, pois, um desrespeito aos valores do mar, ao que se segue a vingança persistente das forças do Índico.

Após o nascimento, a família de Luandle sente-se amaldiçoada, culminando na morte da mãe. Há uma estrutura cíclica, que também contrapõe sonho e morte, e acaba sendo um não-dito do plano diegético e que termina por relativizar a perspectiva escatológica. Assim, sea constante do conto parece ser a praga oriunda do interdito no mar, percebe-se, na estrutura cíclica (fartura/penúria, inundação/seca, morte/vida, sonho/ realidade), e também em algumas descrições do narrador, que, apesar de Khosa abraçar literariamente as componentes tradicionais e mitológicas, as dimensões citadas (motivo cíclico e descrições do narrador) apontam para seu reverso, dessacralizando as explicações e a leitura da totalidade.

Na morte da mãe há a mediação de um sonho, igualmente benfazejo, mas contrariado pela realidade que é boa (pescaria) e má (morte). A mãe sonhara com fartura, pássaros que abocanhavam muitos peixes "até que se fartaram e atiraram-se às águas, morrendo afogados...” (KHOSA, 2008, p. 19). O trecho é compassado e analítico, ao contrário da voracidade narrativa do fluxo que abre a narrativa. $\mathrm{O}$ nascimento é vertiginoso, a morte é calma, descritiva. "Palitou os dentes. Olhou para o mar, para o céu, para a terra, e reteve o olhar nos miúdos que brincavam...” (p. 20). Ao mesmo tempo, a pescaria é bem-sucedida. Luandle estava feliz no mar, no momento em que a mãe morria em terra. A dinâmica entre terra e mar não traz identidades fixas.

A crise põe em cena as descrições às quais nos referíamos. O narrador recorre à historicidade, introduzindo elementos da estrutura social mais complexa, com indícios de política e estratificação social. A costa se torna um lugar de abandono, fazendo evidenciar um próprio abandonar-se a si do mar, com a emergência de ruínas, numa condição de generalização mítica, opondo terra e mar, sem localização geográfica específica, mas nisto não se alienam as pessoas e as relações sociais ali dinâmicas. Não se aponta uma causa para a mudança, apenas se diz da precipitação dos dias. O abandono social das machambas, da pescaria, do comércio, acaba se tornando também o abandono do mar, fazendo emergir navios naufragados, como se o mar também tivesse recuado, acabando com os 
peixes. Khosa, ainda que tenha por projeto literário expresso no conto a aderência aos valores da matéria narrada, ao engendrar contextos sociais acaba por historicizar o próprio motivo mítico, dessacralizando-o nas entrelinhas.

Passamos agora ao quarto movimento (após nascimento, morte e decadência do mar). Não conseguem vender o barco, e pai e filho o abandonam junto a outros já em escombros, queimam a casa e vão "para o interior, esse sertão africano" (KHOSA, 2008, p. 21). Ou seja, o quarto movimento é o da interiorização/sertanização. Ali se aponta outra configuração social, com “capatazes sem patrões” que, pela violência, impedem os pobres de se alimentarem nas machambas. A presença dos "capatazes" é, a rigor, a persistência da estrutura colonial. Há aí um interdito que é também estrutura social. Se elementos fantásticos podem ser invocados aqui, também o podem a dinâmica da guerra e a das intervenções bruscas sobre a vida coletiva e individual.

A ruralização é também o momento em que se evocam indícios não míticos, como a marcação colonial sobre o acesso às terras. O narrador de Khosa indica uma busca esperançosa, alimentada pela contemplação de terras férteis, quando chegam enfim a "uma nesga de terra que lhes era propícia para o cultivo e a construção da casa que levou quatro dias e quatro noites..." (KHOSA, 2008, p. 22). A numeração mítica da construção, acrescida do fato de que chegaram ao lugar num "dia sem registo", após vagarem em busca da terra prometida, são camadas do componente mítico. Não se abdica, porém, do registro social, indicando as composições da estratificação, da distribuição da propriedade e da penúria. O filho se casa e a mulher, Nyelete, fica grávida, mas já na segunda colheita há uma enchente, com destruição da plantação, o que obriga "o pai, filho e nora, já grávida, a subirem à árvore mais alta das redondezas onde ficaram sete dias e sete noites [...]” (p. 23). Ali, veem todo tipo de desgraça, pessoas e animais sendo arrastados pela inundação.

O conto se estrutura na dinâmica de fluxos e refluxos. A partir da narrativa da enchente, porém, cessam os fluxos, sendo, pois, três ao todo: nascimento, migração, enchente. Todos os fluxos humanos se dão, materialmente, em relação ao mar. $\mathrm{O}$ movimento humano em relação às águas ganha no conto todo um poético espelhamento, pois é também o movimento das águas (Luandle, o nome do mar) em relação a elas próprias.

Assim, presos à árvore, a família sofre mais uma virada com o nascimento do filho de Luandle e Nyelete. Nasce na árvore, novamente 
deslocado e sob interdição. Tem-se um clima permanente de desconforto, de nascimentos deslocados e indevidos. A desgraça está sempre espreitando: sina da família ou condição generalizada da pobreza? De fato, há um contexto social da desgraça da família de Luandle que os coloca como uns entre tantos.

No oitavo dia, enfim chega um helicóptero para o resgate. É quando acontecerá outra morte. Assim, ao nascimento de Luandle, sucede-se na narrativa a morte da mãe, após alguns anos. E após o nascimento do filho de Luandle vai se dar a morte do pai. O pai recusa o salvamento, e pede que Luandle dê o nome "da morte" ao filho (Kufeni). Em termos narrativos, a passagem é abrupta como a morte: na sequência já temos Luandle e Niyelete estabelecendo morada numa terra "boa". Instala-se uma vida comunitária, ilustrada no conto pela exploração comum do comércio: os camponeses sendo convencidos à troca da produção de milho por itens agora dados como necessários na nova correlação de forças entre campo e cidade. A cidade impõe aos camponeses produtos novos: "bâton e soutiens e papel higiênico" (KHOSA, 2008, p. 26). Khosa retoma aqui a dimensão perversa da associação entre modernidade e colonialidade. $\mathrm{O}$ pobre aparece na condição de dependência de novos hábitos de consumo. É a partir das considerações sociológicas (além do modelo cíclico) que podemos ler o conto de Khosa como dúplice, ancorado na explicação tradicional de mundo (que se faz projeto estético) e nas cosmovisões racionalizadas (acentuando criticamente a historicidade).

Por fim, no conto, uma última mudança climática, com o predomínio do sol. Nyelete comenta com Luandle ter sonhado com árvores sem frutos. O espaço interior rural passou de verde (na peregrinação) à inundação (o sertão virou mar) e agora entra em nova fase, a da seca. A pobreza se instala, acompanhada da fome. A "praga", que surge ligada a Luandle, é o tempo todo reapresentada, ainda que de modo implícito pelo narrador, como tendo alcance e consequências que estão na vida econômica, na condição ambiental, no agravamento das relações sociais de exploração. A "praga”, portanto, é uma condição presente não apenas na família de Luandle, ainda que os sentidos atribuídos pelas personagens apontem para isso.

A parte final do conto traz mais um sonho/visão associado à morte: Nyelete vai buscar lenha, senta para descansar, passa a imaginar "Kufeni brincando no meio do campo de milho a perder de vista" e "o marido trocando milho na loja” (KHOSA, 20o8, p. 28), e morre. É como se as 
mortes indicassem um sacrifício. A mãe de Luandle morre proporcionando boa pescaria ao marido e ao filho, o pai morre proporcionando liberdade à nova geração, e agora é Nyelete quem morre, sonhando com a fartura para todos. São mortes tranquilas, conscientes:

\footnotetext{
Uma onda desfez-se aos seus pés. As águas recuaram. O mar afastava-se. E ele caminhava, perseguia as águas. A terra secava à sua passagem. Havia montes, depressões, vales. E o mar não voltava. Fugia. Recuava. E ele corria, chorava. E o mar não voltava. (KHOSA, 2008, p. 29)
}

É quando Luandle abre os olhos e se encontra em sua cubata. A pobreza segue, o filho está lá fora, comendo "as crostas das feridas mal saradas que cobriam o corpo” (KHOSA, 2008, p. 29). O pai tenta evitar que o filho coma as próprias peles e sangue, sob a onipresença inenarrável da fome.

O pai de Luandleéa única personagem a ter interioridade. A propósito, tomamos aqui observações de Francisco Noa quanto à atmosfera fatídica na literatura de Khosa. Para Noa (1998, p. 14), o fatalismo ancestral viria correspondido formalmente na "discursividade orgíaca e ininterrupta de Ungulani”. Pensamos diferentemente, porém, quanto à proposição que Noa estabelece quanto à solidão das personagens. $\mathrm{O}$ especialista atribui tal condição ao desajuste entre mundo interior e mundo exterior. Ora, a solidão evidenciada no conto "A praga" apresenta outras variáveis, pois praticamente não há vida interior no conto, sendo apenas o pai de Luandle um ente reflexivo. Depois, o próprio conto não sugere tal distinção: a pouca vida interior do conto não se encontra dissociada da cosmovisão tradicional e das condições materiais de existência.

$\mathrm{O}$ conto, que vinha em ciclos, acaba de modo abrupto e grotesco, como se houvesse terminado a sucessão de ciclos. Ocorre que a perspectiva fundamental da narrativa é a do pai pescador. É ele que assiste ao nascimento de Luandle, ele que conduz a migração para o interior e, quando se suicida, parece-nos que o conto deixa de ter a moldura de um sujeito. Terminar com o menino comendo as próprias crostas é a consagração dessa ruptura com o pai de Luandle. O que nos reconduz ao problema da filiação, dos laços de parentesco como fundamentais à pertença identitária. O suicídio do pai é o rompimento daquela raiz, abrindo espaço definitivo para a consagração da praga que é o comer-se a si mesmo do neto.

Nesse ponto, fica nítida a adesão estético-ideológica de Khosa aos valores tradicionais: o conto estabelece uma rígida partição, dividindo 
homens de mulheres. Se os homens morrem ou são condenados pela água, as mulheres morrem de secura. Ao mesmo tempo, as mulheres têm seus filhos na água. $\mathrm{O}$ pai de Luandle se suicida na enchente. $\mathrm{O}$ filho de Luandle nasce durante a enchente, pelo que recebe o nome da morte. Outro é o destino das mulheres. A mãe de Luandle morre em casa, esperando marido e filho. Narra-se sua morte a partir do contato com o sol: "Tapou as coxas com a capulana e atirou os olhos ao sol que se desembaraçava das nuvens, sorrindo ela e o sol. A morte chegou-lhe calma e serena" (KHOSA, 2008, p. 20). Já com Nyelete, companheira de Luandle, a morte chega pela própria queimação, pois o momento final do conto é o da seca prolongada: "O sol queimou a pele já gasta, percorreu os cabelos queimados, sugou-lhe a pouca força que tinha e obrigou-lhe a fechar os olhos. E então viu tudo" (p. 28).

Existeuma dinâmica entrevida e morte, mare terra, mortes masculinas e femininas. Mas existe também uma dinâmica socioeconômica e de mais difícil entendimento. De fato, há momentos de fartura relativa, ainda que não seja esta a percepção das personagens. É aqui que se nota uma dissociação entre a diegese e certas descrições do narrador (ou mesmo em relação a alguns indícios). Em Khosa, tal questão é complexa, pois há o movimento do mar em relaçãoao próprio mar (Luandle). Suas personagens só saem do mar porque a natureza "vivenciou" um nascimento proibido pela tradição em suas águas e passou a negar a vida à família. Ocorre que sair do mar acaba não resolvendo, pois Luandle é o próprio mar (tem o nome do mar). Assim, a família é atingida por sucessivas vagas: a fuga para o interior, a enchente (marcada pelo nascimento de um filho cujo nome será a tradução de morte, e pelo suicídio do pai, afogando-se naquelas águas da inundação), a morte da companheira de Luandle e, por fim, a autofagia de seu filho, com que se fecha a narrativa. $\mathrm{O}$ mar aqui é quem desfaz as personagens. Nisso, a própria condição da pobreza se amplifica, acrescida dos valores da mitologia. Mais do que a visão mitológica, portanto, o que temos é a pobreza como a própria condenação, isto é, como a praga de fundo material.

\section{CLEMENTE BATA E O OUTRO LADO DO MAR}

Analisando representações da "nação por vir" na literatura colonial moçambicana, como as da continuidade imperial e as autonomistas, 
Francisco Noa (2002, p. 228) argumenta que o espaço é fundamental para se pensar a utopia:

A utopia é sempre a projecção de um lugar ideal, perfeito, muitas vezes, com cintilações paradisíacas. O ponto de vista geográfico, como referência virtual, tem um papel relevante já que o espaço utópico refere-se, quase sempre, a lugares desconhecidos, ilhas isoladas, com o seu grau de pitoresco e descontaminação. Por outro lado, parte-se de uma situação existencial concreta para uma idealização que a transcenda e a corrija. Portanto, é uma orientação para o desconhecido a partir daquilo que é conhecido.

A definição da utopia espacial de Noa tem presença em Clemente Bata, que confere à utopia sua modulação mais essencial. Se as utopias coloniais e autonomistas descritas pelo especialista preveem um lugar profético já delineado, no conto que analisaremos a utopia parece desfazer os binarismos de lugar e não lugar, compondo a questão sob outra chave.

Bata teve publicado no Brasil, pela Kapulana, o livro de contos Outras coisas (2016). A alteridade no título é reverberada no conto "O outro lado do mar". O texto se desenvolve por diálogos, e nisso o narrador se faz quase observador, numa perspectiva horizontal, respeitosa e solidária com as personagens. A própria situação encaminha as sequências, sem que um narrador as conduza ou explique.

O conto se inicia com um diálogo entre João Makhate e Rindza. São marginalizados na cidade e, sob vida precária, vendem limões e devem três meses de aluguel. Sobre Makhate não somos informados, mas de Rindza sabemos que esperava vaga como professora primária e que já fizera tricô e biscoitos para vender. Ela, assim, aposta numa fímbria de estabilidade e conta com um capital cultural que lhe permite apostar em si própria para um salto para fora da pobreza. Makhate faz o gênero da malandragem. Ele se encontra em escala descendente, pois trabalhara na fábrica de pneus, posteriormente falida, sendo depois ajudante de pedreiro, onde acabou se machucando no trabalho.

A malandragem de Makhate se evidencia quando ele anuncia um golpe no qual Rindza deveria ir a um bar, fingir ser irmã dele, dando o bote em algum desavisado que viesse pagar a conta dela. Depois que ele lhe assegura não haver intenção de prostituí-la no golpe, ela aceita e vão ao bar. Sem vítimas prováveis, voltam no dia seguinte. Ela então conversa com um rapaz. Rindza diz ao sujeito estar esperando pelo irmão. Chega Makhate e o golpe consiste em insinuar uma doença familiar para que Tadeu, o rapaz enganado, ofereça dinheiro. 
Quando Makhate sai com o dinheiro, é Rindza quem reencaminha a situação, abdicando do golpe. Diz a Tadeu que devolverá o dinheiro e que já o conhecia do "Bilene", região litorânea do interior. É quando se aproximam, mostrando o percurso de ambos nos últimos anos. Ela tinha ido a Maputo "fazer professorado". Ele fora para a marinha: "Vivo do outro lado do mar" (BATA, 2016, p. 61).

Como se percebe, as forças comunitárias, as raízes regionais, acabam sendo modeladoras do futuro casal (o conto terminará com Rindza e Tadeu juntos), conjugando tradição e modernidade. A confiança apresenta um caráter particularmente híbrido, combinando o apelo a uma legitimidade da tradição (sendo o espaço de origem fundamental) a uma legitimação do tipo moderno, das relações desencaixadas e das trocas de parceiros. Interior e capital são os lugares sociais que simbolizam tal articulação, sendo o mar, nessa relação, um ente em homologia. Assim, se o interior que é também litoral (Bilene) apresenta o mar próximo (o mar dos contos de Khosa e dos pescadores de Craveirinha), mas ao qual não se deseja mais retornar, o mar sugerido pela vida desencaixada da capital Maputo, por onde transitam marinheiros, só pode ser o mar no seu grau transcontinental, isto é, um mar desconhecido, mas promissor: o outro lado do mar.

Passa-se um mês, e Rindza é procurada por Tadeu, que anuncia desejo de casar-se. É quando ela, que já não suporta a vida de mentiras com Makhate, revela-se a Tadeu, conta do golpe etc. Eles se desejam mutuamente, e ele diz: "Quero levar-te ao outro lado do mar" (BATA, 2016, p. 63). O mar aqui é uma utopia e uma fuga, mas bastante mais promissora que a existência cotidiana de pobreza vivida por Makhate e Rindza. O outro lado, não definido, não justificado, apresenta-se melhor que a precariedade já conhecida.

No dia seguinte, Rindza vai encontrar Tadeu e o vê com uma moça. A presença de crianças sugere a ela que a moça é "mulher dele”. Quando finalmente vai reencontrar Tadeu na marinha, ela está num estado nervoso equivalente ao do mar: "Com as mãos apoiadas no mural, observou a fúria do mar a galgar o muro. E alta era a tensão que galgava Rindza [...]" (BATA, 2016, p. 65). Veja-se a homologia entre a fúria do mar e a agitação interior de Rindza. Quem lhe surge à frente é Makhate, com um pacote de dinheiro. É quando Rindza, após uma discussão, atira-se às águas.

O conto conduz para situações próximas às de contos dos demais autores aqui compilados. O suicídio por afogamento está em Khosa, e, 
em Craveirinha, temos mortes causadas pelas condições de exploração do trabalho à margem do Índico. Dinâmicas entre pulsões de morte (quando o desejo se encontra condicionado na impossibilidade da existência social: a periferia do capitalismo e as consequências do modelo colonial) e pulsões de preservação da vida, como a que orienta como um todo o conto de Bata.

Na sequência dos acontecimentos, dois comportamentos masculinos aparecem. O de Makhate é fugir da polícia, para acabar morrendo com um tiro, o que confirma sua condição de aproveitador. Tadeu, por sua vez, salta na água, salvando Rindza. Quando ela acorda na clínica, tudo se esclarece: a moça que ela vira com ele é uma sobrinha. O conto termina com o retorno do convite dele: “- E então... vens ao outro lado do mar? insistiu Tadeu, de joelhos, pegando na mão dela. Rindza sorriu” (BATA, 2016, p. 68).

A estória de amor é pacificadora para as personagens, mas algo sobressai da narrativa, para além do conto de fadas. Há na narrativa de Bata uma diversa concepção de utopia relacionada ao mar Índico. O outro lado do mar, ainda que seja expressão de uma alteridade indefinida, só se constrói porque a figura de Tadeu tem ao menos duas âncoras: uma tradicional (a origem comunitária com Rindza, no Bilene) e outra moderna (ele é um funcionário da marinha, o que lhe dá uma poética condição de estabilidade em pleno mar). A primeira âncora é a da terra de origem, mais segura que a vida na capital. A segunda mostra o mar (em seu outro lado) como promessa de um futuro de algum modo melhor que a vida na capital. Esta última confirma a percepção de terror que a proximidade do mar representa nos contos para as personagens pobres. Mais seguro para os pobres é o que não está à vista: o mar à vista (onde a violência social acontece) é pior que o mar desconhecido. A estabilidade de Tadeu se encontra do outro lado do mar, isto é, pela negação de tudo o que se vivia em Moçambique. O marinheiro dá a dimensão índica utópica, ele (seu sucesso, sua condição de marinheiro) "é” o mar Índico, o além de Moçambique e daquele presente opressivo.

O conto de Bata é aquele em que se promete ir mais longe da terra firme, numa combinação de segurança material da vida estável de um empregado (Tadeu) com a aposta no desconhecido por parte de Rindza que, por ter um conhecimento (podia ser professora), tem confiança para se desencaixar em direção a outra aposta. Se a tradição (o Bilene) é fator legitimador para uma relação conjugal, a aceitação da nova 
vida é inevitável, pois a exploração da vida de uma pobreza marginal já apresentara o lado perverso da modernização a Rindza.

O mar, aqui, é quase a morte (no quase afogamento de Rindza), mas acaba sendo a vida, com direito a amor, estabilidade e uma dimensão simbólica de ir ao encontro de uma alteridade. Pensamos aqui justamente numa outra dimensão de "fazer o mar", como discutida por Falconi (2013), isto é, no modo como os de vida precária podem sonhar em "fazer o mar" e de como um ficcionista consegue mediar sem excessivas intromissões didáticas tal operação narrativa. É por essa condição que definimos a utopia em Bata como uma utopia crítica, na medida em que desfaz a polarização entre tradição e modernidade, mostrando suas específicas configurações no caso da vida pobre no Moçambique contemporâneo. Se Rindza aposta no outro lado sem o conhecer, Bata deixa claro que a projeção para o futuro se faz atrelada ao passado, numa dinâmica em que estabilidade e instabilidade são elementos porosos e deslizantes com relação à polarização de terra e mar Índico.

\section{BORGES COELHO E A CONSCIÊNCIA CRÍTICA DO OCEANO ÍNDICO}

Em 2005 veio à tona a publicação de Índicos indícios. Dividindo a coletânea de estórias pela geografia, Borges Coelho apresentou o livro em dois volumes: Setentrião e Meridião. Elena Brugioni (2015, p. 103) analisou assim a publicação:

Com efeito, nesta obra de Borges Coelho, o Índico não se apresenta como um espaço de evasão ou, melhor, como o ponto de passagem para viagens, buscas e (novas) utopias tal como se configura na poesia contemporânea moçambicana. O mar Índico é nos Indícios o lugar inaugural da narração, o indício de uma história maior, um espaço físico e conceptual a partir do qual é possível (re) definir a geografia imagética e telúrica moçambicana. Por outras palavras, obedecendo a uma inversão de perspetiva, o mar torna-se um arquivo líquido, um repositório de memórias e rastos que são matriciais para dar sentido aos enredos e às histórias que edificam o mosaico social e cultural moçambicano.

Gostaríamos de tomar, dessa citação, a noção de "arquivo líquido”, na medida em que se relaciona diretamente à sucessão de perspectivas que se debruçam sobre o sumiço do mar num conto de Meridião, chamado "A força do mar de Agosto". Pensamos o arquivo líquido um pouco além do objeto histórico, na medida em que emergem do conto também as 
molduras de apreensão das estruturas históricas, isto é, as perspectivas (as dos moradores, mas também as das instituições e seus aparelhos de poder cartográfico). Em termos narrativos isso se processa numa amplificação crítica, racionalizante e irônica do narrador, que estabelece diálogo entre as suas perspectivas e as das personagens e instituições, tecendo uma malha discursiva complexa sobre a qual detém a palavra final (o segredo do conto). A construção narrativa do autor é similar à prática do artifício. A brincadeira é um componente explicitado na própria moldura do conto, que abre e fecha com a mesma ação de um menino que atira a pedra ao mar para a ver saltitar à superfície.

Borges Coelho consegue a síntese entre o mar da superfície e o mar da profundidade, entre o mar próximo e aquele distante, ressaltando a hibridez e a heterogeneidade índicas. $\mathrm{O}$ mar, aquele das perspectivas usuais, as dos seus usuários mais permanentes, os pescadores e as vendedeiras pobres, mas também daquelas perspectivas para além da própria capacidade de visualização humana, as das instituições e suas máquinas de ver as profundidades, acaba, no conto, justamente pelo desvelamento que a invisibilidade lhe confere, tecendo um outro arquivo líquido, no qual se fundem passado e presente (e tendo por vítimas involuntárias os moradores pobres).

Em "A força do mar de Agosto", o mar aparece em várias dimensões: na dimensão histórica (a acumulação de histórias de naufrágios revelados), na dimensão geográfica (a baía de Maputo, a ilha da Inhaca, o Catembe, a Xefina, a Austrália), na dimensão material (fonte de subsistência), na vinculação a uma ordem sazonal (o cacimbo típico do mês de agosto responsável pela ilusão de ótica que fez o mar desaparecer).

Para chegar às narrativas propriamente ditas, parte-se em Borges Coelho de mediações, como da noção de oceano, evidente no nome da coletânea, Índicos indícios. O próprio plural nesse nome é indicativo das possibilidades de enfoque: o Índico é múltiplo no autor. São indícios de Índico, mas não a sua totalidade homogênea. Indício não significa o realismo fotográfico, mimético, mas indiciário e até mesmo intuitivo.

Há, no título da coletânea, a dimensão do mar enquanto oceano, partilhada pelo autor com os leitores, o que contrasta, como dissemos, com as percepções do mar por moradores pobres. É assim que as “estórias" serão percebidas no nível diegético: o mar, local, em sua dimensão material, palpável; o Índico, oceano, em sua dimensão imaginada. O procedimento das estórias "ateadas" assinala que a inexatidão poética da 
evocação caminha em conjunto com a exatidão dos lugares. Abre-se mão da objetividade histórica em prol da exaltação do ficcional - o que nos leva a pensar em uma escrita que se faz simultaneamente histórica e literária.

A voz do próprio autor predomina no processo de aproximação da matéria narrada, pelo qual o leitor passa até a chegar nas narrativas propriamente ditas. Antes mesmo dos contos, o autor nos coloca diante de um prefácio (ainda que não textualmente indicado como tal) em que, valendo-se de sua autoridade, ele não apenas apresenta as narrativas que serão lidas, mas sugere modos de leitura. Sobre o conto em questão, afirma: “contra a corrente dos outros textos, 'A força do mar de Agosto' comprova que, sendo pesado, o mar Índico também pode ser transparente; tal como, cedo ou tarde, acabam por desnudar-se os nossos desígnios mais obscuros" (COELHO, 2005, p. 10).

Como nos contos aqui já escrutinados, nossa ênfase irá se concentrar na movimentação e na configuração do espaço. Nesse aspecto, concederemos especial atenção ao narrador, pois é através dele que se estrutura a percepção do espaço Índico. Entendemos que no autor se enfatiza a condição não referencial: são estórias "ateadas", como nos diz o escritor. Outros especialistas já se debruçaram sobre essa condição de Borges Coelho. Muitas análises de sua obra tomam por objeto a concepção espacial. Citando análise de Roberto Vecchi a respeito da condição espacial dos Índicos indícios, Nazir Can (2017, p. 23) escreve:

Privilegiando um processo de reescrita do espaço, mais próximo da topoi-grafia do que da cartografia, através do qual se dá a reconfiguração do próprio tempo histórico, [...] as narrativas de JPBC avançam na contramão da história oficial, assumindo-se como formas de exceção (enquanto escrita) que inscrevem exceções (enquanto temas).

Nada mais próximo das nossas observações: a inscrição da exceção (o sumiço do mar) é justamente o desvelamento de uma prática de escrita igualmente única, pois reconfiguração do cotidiano histórico a partir do desvelamento do fantástico, ressaltando a literariedade ficcional.

Em Rita Chaves (2006, p. 188), a questão do espaço é pensada em Borges Coelho a partir da incorporação "em seu imaginário [de] espaços que o país independente ainda conhece pouco". Chaves identifica no autor uma descrição obsessiva que revelaria a especificidade poética de diversa concepção de tempo. Pensamos, no entanto, ser problemática a associação de tal geografia plural à dimensão de política da integração nacional. Para Chaves (p. 190), haveria no ficcionista o compromisso e o 
desejo de empenhar a atividade literária no processo de integração nacional, investindo, portanto, na proposta que as forças políticas responsáveis pela independência defendiam mas não foram capazes de realizar.

Ainda que possa haver tal projeto intelectual no autor, sua literatura nos parece apontar para uma modéstia mais especificamente literária, recusando-se às imaginações de comunidades. Integração não nos parece ser o projeto literário do autor, de literatura não mimética e mesmo muitas vezes recusando-se à pertinência geográfica. Assim, o que Vecchi (2012, p. 21) escreveu para pensar a relação entre história e literatura no autor moçambicano, também se estende à relação entre geografia e literatura. Os mapas são ponto de partida, nunca de chegada, ficando à margem do ficcional, não o invadindo.

Na mesma linha de análise, temos o volume Visitas a João Paulo Borges Coelho (KHAN et al., 2017), obra que traz alguns ensaios que discutem aquela dimensão topológica enunciada por Vecchi. Há ensaios sobre as "pontes", sobre os "rios", sobre as "ilhas" etc. Pensamos que, do mesmo modo que as "pontes", analisadas por Nazir Can como "poética fundada no trânsito entre a separação e a união, entre o que foi e o que poderia ter sido, entre o esquecimento e a lembrança, entre História oficial e memória quotidiana [...]" (p. 71), também o mar, descrito no conto na figura da baía de Maputo, possibilita uma travessia ao desvelar as relações entre visibilidade e invisibilidade, entre natureza e cultura (as práticas cotidianas da vida urbana litorânea), entre vida ao rés do chão e aparatos institucionais da hierarquia geopolítica, entre vida comunitária, especulação imobiliária e existências atomizadas e, por fim, entre o mar vivido e o Índico poeticamente imaginado. Há, portanto, também um outro lado do mar (como evocado no conto de Clemente Bata), mas de dentro do mar, com a história e o relevo.

O conto se abre com a baía acordando vazia, e a seguir aparecem os protagonistas, os "moradores", que surgem de modo coral. As vagas de pessoas no autor evocam a voz coletiva do povo, como o coro grego clássico. As percepções se sucedem. Primeiro, pensa-se apenas num mar “quieto". Depois, inaugura-se o enigma empírico no qual os moradores vão constatando uma diferença que não é exatamente a da ausência da água, mas uma espécie de água "outra". Assim, não é à ausência de água que se refere o primeiro pescador, mas ao fato de que "a sua pele não brilhava como normalmente o faz quando é lambida pela água. [...] (antes seria água, hoje já não sabia)" (COELHO, 2005, p. 126). O "não sabia” indica 
que há algo à maneira de água naquela baía. Está em jogo, portanto, a "força" do mar de agosto: tão forte que pode desaparecer e reaparecer, como se verá ao fim do conto. As sucessivas vagas perceptivas operam o desvelamento pelo absurdo.

Borges Coelho retrata a população pobrea partir de um distanciamento que põe em contraste o narrador e as personagens. O narrador tem um olhar de cima, operando por sobrevoo. De fato, ele se encontra com a perspectiva global e com uma objetividade algo de almanaque (no limite do kitsch), pois junta materiais heteróclitos em pé de igualdade. Expõe, por exemplo, a ruptura do padrão de gênero que orienta a subsistência no litoral de Maputo, pois o fenômeno do desaparecimento do mar conduziu a que pescadores e vendedeiras trocassem de funções (os peixes vieram à tona, gerando a troca de papéis). Prossegue o narrador expondo as consequências lógicas do fenômeno ilógico do desaparecimento do mar, isto é, parte do absurdo para analisar as situações em termos antropológicos, verificando o sentido de uso que os moradores fazem em relação ao mar.

A operação narrativa se dá com significativas mediações, contrastando as percepções das personagens entre si, e com a do próprio narrador: esta é a única voz que fala ao leitor, sendo o discurso direto todo intermediado. Há ironia constante, figuras de linguagem, especialmente analogias. Estamos diante de um olhar cientificista, mas que contrasta com sua aceitação do desaparecimento do mar. $\mathrm{O}$ narrador não problematiza o desaparecimento do mar, mas sim as consequências do fato.

Temos, pelo narrador, a percepção do desaparecimento do mar como desastre. Descreve-se uma sequência de entidades estatais que fracassam na investigação: "uma guarda avançada da Polícia Municipal", a "Brigada dos Técnicos a fim de levar a cabo um estudo em maior profundidade” (COELHO, 2005, p. 130). Citam-se as ferramentas utilizadas: réguas, compassos. A seguir, investigam o cano do esgoto (que seria a hipótese dos pescadores), uma "calamidade tectónica qualquer" e, novamente, não se acha a resposta para o sumiço. Como dissemos, o narrador detém um segredo e, como numa aula de mágica, revelará a causação ao final.

Há uma hierarquia de soluções apresentadas para o escrutínio do que fora o mar. As soluções locais apresentadas são absurdas, como construção em maquete de uma descarga gigante, como se a baía fosse um grande vaso sanitário. Os moçambicanos desistem e recorrem a contributos estrangeiros. Os vizinhos sul-africanos já tinham fotografias aéreas da 
região porque quiseram ali instalar bases militares e cano de gás partindo de Moçambique. O Índico sul surge na sua dimensão transnacional contemporânea, na hierarquia de epistemologias de investigação.

O mapeamento do fundo do mar pelos sul-africanos revela o esquecido: um avião desaparecido, corpos de marinheiros afogados e inúmeras embarcações. Todos os acidentes têm suas histórias contadas pelo narrador, mostrando ao leitor domínio total da matéria narrada no plano histórico, sendo o mar aqui um "arquivo líquido", à maneira de cemitério. Com o fracasso das soluções apresentadas pelos sul-africanos, entram em cena os estadunidenses. Fotografam a baía por satélite, mas nada é encontrado.

Por fim, dá-se a interferência estatal direta no processo: "desistindo da tecnologia de ponta para se virar para soluções mais tangíveis, as ditas nossas soluções" (COELHO, 2005, p. 135). Desenha-se um mapa, um projeto de urbanização da área ao modelo capitalista de terceiro mundo, com uma urbanização que visa ao lucro apenas. Em suma, ocorre a gentrificação do mar. Citam-se taxações, fazem-se reflexões sobre o Estado e sua ineficiência, sobre a cobiça de grandes empresas etc. Borges Coelho faz aqui também um arquivo das forças econômicas e políticas que atravessam de modo local, nacional e transnacional o Índico. A transnacionalidade é uma dessas linhas de força.

A reflexão final nos diz sobre a condenação dos pobres à subsistência no mar. Os moradores da costa, "da extinta praia da cidade; o lado de onde veio a maior resistência” (COELHO, 2005, p. 138), são pescadores que reivindicam a posse da terra:

\footnotetext{
Não havia contudo registros notariais que apoiassem aquela sua pretensão, só lendas vagas; de modo que nestes tempos de legalidade e de justiça, em que são insuficientes as boas intenções, ela não vingou. Ficassem onde estavam, e por ser terra já seca, fizessem agricultura.
}

Após, portanto, a condenação à reiteração da pobreza, o narrador oferece, à maneira de compensação social, o retorno do mar. Há o fechamento de ciclo e o retorno ao realismo que abre o conto - o fim da desordem é o retorno à "normalidade".

Na narrativa de Borges Coelho evidenciam-se as diferentes relações que se estabelecem a partir do mar: a dependência econômica dos pobres, ao mesmo tempo em que os ricos e o governo veem o (suposto) desaparecimento do mar como oportunidade. A baía de Maputo, enfim, acaba adquirindo uma condição utópica, fantástica, na imagem remetida 
pelo cacimbo. Sacrifica-se, desse modo, a existência dos sujeitos e a estrutura social em detrimento da poesia que emerge das imagens da névoa sobre o mar. Ao contrário dos outros contos, nos quais as personagens se movimentam em relação ao mar, nesse conto de Borges Coelho o que se movimenta são as percepções sobre o mar, num jogo contrastivo entre as percepções das personagens, instituições e, fundamentalmente, as do narrador.

\section{CONSIDERAÇÕES FINAIS}

Propusemos neste ensaio uma outra abordagem da representação do mar Îndico na literatura moçambicana. Para além dos importantes, mas usuais, objetos de maior teor do imaginário índico (como a Ilha de Moçambique, a produção poética etc.), optamos pela análise de uma dupla representação: a de personagens pobres às voltas com o mar. Relações sociais e representação espacial, portanto. Quisemos adensar a discussão do imaginário transnacional do Îndico a partir de sua concepção como uma das linhas de força que atravessam situações cotidianas relacionadas à subsistência à margem do mar. Vimos como os contos articulam as dinâmicas econômicas da presença do capitalismo na periferia mundial às dinâmicas de movimentação física e de pulsões de vida e morte das personagens. Vimos, também, que no conto de Borges Coelho pode-se vislumbrar uma leitura crítica contrastiva entre diferentes imaginações, diferentes modos de ser e fazer o Índico.

Borges Coelho foi tomado aqui como contraponto, pois faz o mar se movimentar, e não as pessoas. Pessoas que, no seu conto, são anônimas (o menino que atira a pedra à água, os pescadores, as vendedeiras). Nos outros contos, pessoas com nomes movimentam-se em relação ao mar. Em Khosa, o mar está também na própria personagem Luandle, o que institui um outro modelo de movimento, que pode ser justaposto ao da narrativa de Borges Coelho. Se neste o mar inicia o jogo de movimentos e as pessoas passam a se orientar por ele, em Khosa mar e indivíduo se movem juntos, com momentos de fartura e tragédia, ainda que o conto se chame "A praga". Craveirinha, por sua vez, destacava a absoluta dependência dos pobres à margem do Índico, tomando o mar como figura do carrasco colonial e das demandas da estratificação contraditória. Em Clemente Bata vimos a demanda do outro lado do mar, utopia necessária à negação, pela esperança, da pobreza. No conto desse autor, o casal tem 
uma origem comum: a dimensão familiar/regional/tribal é uma constante na vida pobre. Assim, o outro lado do mar é algo tão significativo por ser promessa de estabilidade e felicidade para além das tragédias da pobreza. No pertencimento à terra tribal que dinamiza a relação com o mar, temos uma questão teórica importante, a do alcance epistemológico de noções nacionais ou transnacionais para se pensar a representação da pobreza. Por isso optamos pela discussão das mobilidades, das vagas de gente e das vagas do mar postas em dinamismo.

Tais mobilidades são índices de uma estrutura social em suas manifestações históricas coloniais, revolucionárias ou neoliberais. Todas apontam para o fato em comum de que a mobilidade nas literaturas periféricas tende a considerar mais o dado físico que o realismo interior, de apreensão psicológica. Se, na ficção canônica eurocêntrica, o conflito se dá entre vida interior e mundo social (por exemplo, o casamento por amor, entre classes diferentes), a diversa configuração histórico-social da nação moçambicana (e das nações índicas), mostra como tal movimentação acaba sendo obtida pelos ficcionistas num plano da movimentação física. Isso mostra a transitoriedade, precariedade e gratuidade da vida pobre em condições de economias dependentes e periféricas. A solidão/ subjetividade burguesa, típica do romance europeu, não se faz presente nos contos analisados.

Pode-se pensar, então, na especificidade da modernidade presente nos contos aqui discutidos. Como vimos, as pressões da subsistência em relação à natureza conduzem a uma outra relação de trabalho na vida pobre. Igualmente, mas em outra via, destacamos as condicionantes da tradição (a forma mítica operada por Khosa, a estrutura de sentimentos tradicionais compartilhada pelo casal que se constrói em Bata) como inerentes à relação, seja com a condição de inserção na economia global do mar Índico (o que especifica tal sujeição dos pobres à natureza), seja com a presença de um imaginário transcontinental operado no plano da cultura material. Erige-se, assim, uma modernidade especificamente local. Diríamos, com Partha Chatterjee (2004, p. 46), que "aquilo que outros pensam ser moderno seja inaceitável para nós, assim como aquilo que estimamos como elementos valiosos da nossa modernidade não sejam em absoluto considerados modernos por outros”. O ponto central, para o autor, é que determinadas modernidades periféricas não abdicam da presença da tradição, alimentando-se dela. 
Com exceção de Borges Coelho, poderíamos dizer que aquela movimentação das personagens se dá num plano em que a força mais importante é a do mar, de onde se extrai o sustento ou a utopia. Não há a ideia de praia, tal como pensada nos balneários turísticos e na representação cultural do mundo ocidental a partir do século XVIII. A praia, para Alain Corbin (1989), surge na vida moderna ocidental como espaço de práticas burguesas: a estação balnear, repouso e cura do corpo e do espírito; o ponto de sociabilidade das elites cultas; a vida urbana e o regramento do mundo do trabalho a partir da constituição das férias. Em termos estéticos, essa racionalização da praia conduziu do sublime (o mar como abismo, devoração, infinitude natural) ao pitoresco domesticado.

Essa dimensão metropolitana, turístico-pitoresca, que tenderia a ressaltar mais explicitamente fenômenos e práticas interculturais de especificidade índica (a paisagem, a cultura material, a culinária) acaba ausente da perspectiva de contos que se voltam primordialmente para uma apreensão material dúplice: o mar enquanto fonte de subsistência é também o mar terrível e esteticamente sublime. Borges Coelho, ao racionalizar o mar (expondo-nos, paradoxalmente, um absurdo) é quem introduz a dimensão pitoresca na abordagem do topos. Trabalha-se ali com um espetáculo de óptica limitado (como ensina o modo pitoresco de abordagem) à baía de Maputo, permitindo a inscrição do espetáculo num quadro. O pitoresco é a racionalização (o controle) da perspectiva sublime. O narrador é o único que sabe o que se passou, conhecendo o fim da história. Os contos dos outros autores não apreciam esteticamente o mar como se dá em Borges Coelho. A própria racionalização científica do absurdo (o mar que some) no conto do autor apela à estetização, no fenômeno que só no mês de agosto poderia ocorrer:

O cacimbo, aquecido por um sol que se fortalecia à medida que subia a encosta do dia, começou a liquefazer-se e com isso se desfizeram os seus secretos jogos de espelhos e reflexos, mágicos e tortuosos caminhos da visão: afinal havia mar, só que tão quieto e transparente, tão leve e tão etéreo que passara despercebido! (COELHO, 2005, p. 138)

Tal epifania compreensiva aparece perto do fim do conto, sendo sucedida por parágrafos que retomam lentamente a vida do trabalho, fazendo voltarem os moradores e suas práticas. O que se tem em Borges Coelho, à diferença dos outros contos discutidos, é a suspensão de tais práticas e do sofrido cotidiano material. A suspensão é picaresca, mas 
igualmente poética, apontando para o "não-dito" (CAN, 2013, p. 99), sendo aqui o não enxergado, algo tão presente na literatura do ficcionista.

Tais considerações são importantes se queremos aprofundar a matriz índica da literatura moçambicana. Noa (2014) aponta que a predominância da matriz telúrica na literatura moçambicana deve ser pensada à luz da pertença a um lugar. Pensamos haver aí um duplo movimento, aqui representado nos contos: a movimentação geográfica das personagens, indo e vindo ao mar, tem seu correlato político (o projeto literário da nação colonizada) na constituição de uma soberania simbólica, sempre tensa e a perigo, dentro de um território. O mar, paradoxalmente, na sua dimensão relacional de não lugar em relação aos territórios que compõem a vida social, acaba funcionando nos contos como uma perspectiva crítica, desterritorializante e violenta para a perscrutação da vida dos pobres que com ele se relacionam sob o signo da dependência absoluta.

\title{
BY THE MARGIN OF THE INDIAN OCEAN: THE POOR AND THE SEA IN MOZAMBICAN SHORT NARRATIVES
}

\begin{abstract}
From reading of five Mozambican short narratives, this essay intends to debate the issue of double representation: poor characters and the Indian Ocean. The short narratives that will be analysed are: "História de Sonto: o menino dos jacarés de pau" (José Craveirinha), "Ziche pescador" (José Craveirinha), "A praga” (Ungulani Ba Ka Khosa), “O outro lado do mar" (Clemente Bata) e "A força do mar de Agosto" (João Paulo Borges Coelho). The issues here debated take into account the sea as a survival space for the poor characters. We intend to analyse the representations of the sea taking characters and narrators as a starting point. The economic structure is shaped as an essential factor for a better understanding of the various forces that compose the feeling of identitarian belonging: the local, the national, the transnational. It is given, therefore, special attention to the mobility dimension in relation to the sea and the geographical space in land. It is suggested that such space mobility is constituted as a privileged way of understanding the possibility of modernity in the Mozambican short stories. We conclude that, in the stories analysed, there is a dichotomy between the representation of the sea and the Indian Ocean dimension of a transnational imaginary. If the sea is represented in the narratives as a force of both attraction and repulse from the perspective of everyday survival, the transnational dimension of the Indian Ocean can be seen less as imaginary and more as a significantly structured force of line regarding the life of the poor, conditioning their marginalized mobility.
\end{abstract}

Keywords: mozambican short narratives; Indian Ocean; poor characters.

\section{REFERÊNCIAS}


À margem do Índico: os pobres e o mar em contos moçambicanos - 144

AMIN, Samir. O imperialismo, passado e presente. Tempo, n. 18, 2015, pp.77-123. Disponível em: <http://www.scielo.br/pdf/tem/v9n18/v9n18ao5>. Acesso em: 12 out. 2017.

BATA, Clemente. Outras coisas: contos. São Paulo: Editora Kapulana, 2016.

BRUGIONI, Elena. Por detrás de tantos nomes, o mar. Moçambique e o Oceano Índico: discursos, imaginários e representações. Revista Via Atlântica, n. 27, 2015, pp. 94-110. Disponível em: <https://www.revistas.usp.br/viaatlantica/article/ view/99139/107119>. Acesso em: 14 nov. 2017.

BRUGIONI, Elena. Literaturas africanas comparadas e Oceano Índico. Contrapontos críticos para uma reflexão em torno do romance histórico no Índico africano. E-cadernos Ces, n. 26, 2016, pp. 30-51. Disponível em: <http://journals.openedition. org/eces/2102>. Acesso em: 18 nov. 2017.

BRUGIONI, Elena. Narrando o Índico. Contrapontos entre paradigmas críticos e representações: João Paulo Borges Coelho e M. G. Vassanji. Revista Lusófona de Estudos Culturais, v. 2, n. 1, 2014, pp. 35-53. Disponível em: <http://estudosculturais. com/revistalusofona/index.php/rlec/article/view/67>. Acesso em: 25 mar. 2018.

CAN, Nazir Ahmed. Índico e(m) Moçambique: notas sobre o outro. Diacrítica, v. 27, n. 3, 2013, pp. 93-120. Disponível em: <http://www.scielo.mec.pt/scielo.php?script=sci_ abstract\&pid=So8078967201300300007>. Acesso em: 9 out. 2017.

CHATTERJEE, Partha. Colonialismo, modernidade e política. Salvador: Edufba, CEAO, 2004. Disponível em: <http://www.scielo.br/scielo.php?script=sci_ nlinks\&ref=000122\&pid=S2316-4018201400010001400010\&lng=pt $>$. Acesso em: 25 mar. 2018.

CHATTERJEE, Partha.. Para além da história: Campo de Trânsito de João Paulo Borges Coelho. Via Atlântica, n. 16, 2009, pp.105-117. Disponível em: <http://www.revistas. usp.br/viaatlantica/article/view/50466/54578>. Acesso em: 14 out. 2017.

CHAVES, Rita. Notas sobre a Ficção e a História em João Paulo Borges Coelho. In: RIBEIRO, Margarida Calafate; MENESES, Maria Paula (Orgs.). Moçambique das palavras escritas. Porto: Edições Afrontamento, 2008, pp. 187-198.

COELHO, João Paulo Borges. Índicos indícios I: Setentrião. Lisboa: Editorial Caminho, 2005 a.

COELHO, João Paulo Borges. Índicos indícios II: Meridião. Maputo: Ndjira, 2005b.

CRAVEIRINHA, José. Hamina e outros contos. Maputo: Editora Ndjira, 1996.

CRAVEIRINHA, José. Antologia poética. Org. Ana Mafalda Leite. Belo Horizonte: Editora UFMG, 2010. 
FALCONI, Jessica. Para fazer um mar: literatura moçambicana e oceano Índico. Diacrítica, v. 27, n. 3, 2013, pp. 77-92. Disponível em: <http://www.scielo.mec.pt/pdf/dia/v27n3/ v27nzao6.pdf>. Acesso em: 9 nov. 2017.

KHAN, Sheila. Ler o "Sul" em viagem: duas epistemologias literárias do sul global em Hinyambaan e em Um estranho em Goa. Via Atlântica, n. 17, 2010, pp. 29-42.

KHAN, Sheila et al. Visitas a João Paulo Borges Coelho: leituras, diálogos e futuros. Lisboa: Edições Colibri, 2017.

KHOSA, Ungulani Ba Ka. Orgia dos loucos. Maputo: Alcance Editores, 2008.

LEITE, Ana Mafalda. Oralidades E escritas pós-coloniais: estudos sobre literaturas africanas. Rio de Janeiro: EdUERJ, 2012.

LEITE, Ana Mafalda. Ensaios sobre literaturas africanas. Maputo: Alcance Editores, 2013.

MATUSSE, Gilberto. A construção da imagem de moçambicanidade em José Craveirinha, Mia Couto e Ungulani Ba Ka Khosa. Maputo: Livraria Universitária, UEM, 1997.

NOA, Francisco. A escrita infinita. Maputo: Livraria Universitária, UEM, 1998.

NOA, Francisco. Império, mito e miopia: Moçambique como invenção literária. Lisboa: Editorial Caminho, 2002.

NOA, Francisco. Modos de fazer mundos na actual ficção moçambicana. In: Chaves, Rita; Macedo, Tania (Org.). Marcas da diferença: as literaturas africanas de língua portuguesa. São Paulo: Alameda, 2006.

NOA, Francisco. A letra, a sombra e a água - ensaios E dispersões. Maputo: Texto Editores, 2008.

NOA, Francisco. L'océan Indien et les routes de la transnationalité dans la poésie mozambicaine. Études Littéraires Africaines, n. 37, 2014. Disponível em: <https:// www.erudit.org/fr/revues/ela/2014-n37-elao1494/1026248ar/>. Acesso em: 20 nov. 2017, pp. 73-87.

ORBIN, Alain. Do território do vazio: a praia e o imaginário ocidental. Trad. Paulo Neves. São Paulo: Companhia das Letras, 1989.

ORTIZ, Renato. Um outro território - ensaios sobre a mundialização. São Paulo: Olho d'Água, 2000.

PADILHA, Laura Cavalcante. Nas lavras das literaturas africanas modernas ou sobre novas cartografias identitárias. In: GALVES, Charlotte; GARMES, Helder; RIBEIRO, Fernando Rosa (Orgs.). África-Brasil: caminhos da língua portuguesa. Campinas: Editora da Unicamp, 2009. 
À margem do Índico: os pobres e o mar em contos moçambicanos - 146

VECCHI, Roberto. Letterature postcoloniali e politiche di restituzione: la narrativa di João Paulo Borges Coelho. Tintas - Quaderni di Letterature Iberiche e Iberoamericane, n. 2, 2012, pp. 19-24. Disponível em: <https://riviste.unimi.it/index.php/tintas/article/ viewFile/2769/2982>. Acesso em: 12 out. 2017. 